\title{
A divulgação pública da ciência em prol do desenvolvimento do Vale do Paraíba
}

\author{
The public disclosure of science in the process of regional Vale do Paraiba \\ development \\ Jefferson Martins ${ }^{1}$ \\ (jeff_martins@uol.com.br) \\ Mônica Franchi Carniello ${ }^{2}$ \\ (monicafcarniello@gmail.com) \\ http://dx.doi.org/10.5216/cei.v16i2.25865
}

\begin{abstract}
Resumo
Este artigo visa o estudo da divulgação pública da ciência no processo de desenvolvimento regional voltado para a Região Metropolitana do Vale do Paraíba. Tal observação toma como ponto de partida a possibilidade de transmissão da informação científica através da rede mundial de computadores; e investiga o potencial deste meio para a finalidade de comunicar ciência publicamente. As reflexões aqui desenvolvidas devem contribuir para a ampliação do debate acerca da importância e do papel do conhecimento científico no amadurecimento de uma sociedade atuante e representativa junto ao poder público. Esta pesquisa descritiva fez uso de fontes de papel e de levantamento junto a pesquisadores da região para discorrer sobre os temas pretendidos. Ao final, a dissertação argumenta sobre as possibilidades de desenvolvimento social, político e econômico de uma sociedade cuja comunicação pública da ciência esteja disponível e acessível; com especial atenção às especificidades da comunicação on-line voltada à região valeparaibana.
\end{abstract}

Palavras-chave: Desenvolvimento regional. Divulgação científica. Divulgação científica regional. Divulgação científica on-line.

\begin{abstract}
This paper aims to study the public disclosure of science in the process of regional development facing the Metropolitan Region of Vale do Paraiba. This observation takes as its starting point the possibility of transmission of the scientific information through the world wide web, and investigates the potential of this medium to the purpose of communicating science publicly. The reflections herein developed should contribute to the broadening of the debate about the importance and the role of the scientific knowledge in the maturity of an active and representative society with the government. This descriptive study made use of paper sources and survey next to researchers in the region to discuss the intended issues. At the end, the dissertation argues about the social, politic and economic development possibilities of a society whose public communication of science be available and accessible, with special attention to the specificities of the on-line communication, facing the valeparaibana region.
\end{abstract}

Keywords: Regional development. Scientific disclosure. Regional scientific disclosure. On-line scientific disclosure.

\footnotetext{
${ }^{1}$ Mestre em Planejamento e Desenvolvimento Regional pela Universidade de Taubaté. Especialista em Jornalismo Científico professor universitário, freelancer para agência Futura Press (São Paulo) e proprietário do Estúdio Fotográfico Jeff Martins (Lorena SP). Ministra cursos e workshops de fotografia.

${ }^{2}$ Graduação em Comunicação Social pela Pontifícia Universidade Católica de Campinas (1993), Mestrado em Comunicação e Letras pela Universidade Presbiteriana Mackenzie (2000) e Doutorado em Comunicação e Semiótica pela Pontifícia Universidade Católica de São Paulo (2005)
}

Comun \& Info, v. 16, n. 2, p. 23-39, jul./dez. 2013 


\section{Introdução}

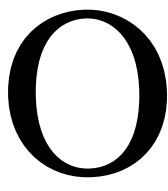

tema deste estudo é a Divulgação Pública da Ciência; e toma por esse termo a divulgação nos meios de comunicação de massa que, em linguagem coloquial, manifestam-se em impresso (jornais e revistas), pela internet, via rádio ou televisão. A pesquisa partiu de observações sobre a organização e a apresentação, junto à mídia, dos assuntos relacionados à ciência desenvolvida na Região Metropolitana do Vale do Paraíba (RMVP), as quais firmaram forte suspeita de não haver uma percepção regional sobre as questões científicas regionais. O grande público apresenta-se à margem da ciência por desconhecê-la e, mais ainda, pela dificuldade em acessá-la. Conforme constatado na literatura, tal fato é preponderante na discrepância social existente em países em desenvolvimento, cujos assuntos científicos passam ao largo dos cidadãos e fundamentam a “Analfabetização Científica” em plena Sociedade da Informação.

Assim, este estudo busca entender o que é e como funciona a dinâmica da produção do conhecimento científico e de que modo se estabelece a comunicação desse saber à Região Metropolitana do Vale do Paraíba. Busca-se, adiante, identificar aspectos que possam favorecer o processo de desenvolvimento dessa região a partir das reflexões aqui apresentadas.

\section{Desenvolvimento e desenvolvimento Regional}

Sabe-se que diferentes áreas do conhecimento fazem diferentes abordagens sobre regiões, conforme apontam Lemos (1988) e Vieira (2009). Lemos (1988, p. 400) afirma que uma região pode ser definida como "o conjunto de pontos no espaço que tenham maior integração entre si do que em relação 'ao resto do mundo"”. Ampliando a análise, chega-se à definição um tanto mais abrangente, presente em Brandão (2009) que afirma que é preciso entender a região como produto de um processo histórico de construção, onde se firmam as relações sociais; um espaço habitado e vivo, que considera sua formação, além da paisagem natural, a partir dos espaços econômicos, sociais, culturais e políticos.

O Vale do Paraíba apresenta um conjunto de pontos no espaço, contíguos e integrados entre si, e é, conforme atestam Martins, Santos e Carniello (2012a), palco de relações econômicas, políticas, sociais e culturais durante os diversos ciclos econômicos da história do Brasil. Ao observar-se as considerações de Martins, Santos e Carniello (2012b) sobre o patrimônio científico 
valeparaibano, nota-se que este tem origem desde a presença de viajantes europeus no século XIX, denotando, também neste campo, amplo quadro histórico a ser considerado.

Essa região desempenhou importante papel na trajetória socioeconômica do país, desde o período colonial.

O movimento do capital e suas determinações sobre a conformação da região do Vale do Paraíba tal qual se conhece atualmente, aparecem, sobretudo, a partir do pós-guerra, nos anos 1950; período em que o Vale intensifica o processo de urbanização. Afirma Vieira (2009) que, neste momento, o Brasil necessitava suprir a demanda interna, alavancando a produção através da substituição das importações. Segundo os pesquisadores, tal manobra atinge o Vale do Paraíba com chegada da rodovia Presidente Dutra, em 1951, em torno da qual as cidades vão se desenvolver e urbanizar.

Observando-se as Séries Históricas (SEADE) entre os anos 1940 e 1960, constata-se que as cidades fora do eixo da Rodovia Presidente Dutra perderam consideravelmente suas populações. Já as cidades localizadas à margem da rodovia indicaram variação considerável de suas populações no período, destacando-se, principalmente, o aumento populacional em 88,69\% em Taubaté, 105,27\% em Lorena e 112,22\% em São José dos Campos. Essa condição perpetuou a conformação atual da região e essas cidades à margem da rodovia continuam mais populosas, com taxa média de urbanização (97,65\%) superior à média do Estado (95,94\%) (SEADE, 2010). Confirma-se, portanto, que o surgimento da rodovia principiou a infraestrutura da qual o planejamento de políticas públicas das décadas subsequentes tiraria proveito. A política do governo federal instalou ali, em 1950, o Instituto Tecnológico de Aeronáutica (ITA) e, através de capital estrangeiro, chegaram as multinacionais Rodhia (1946), Johnson \& Johnson (1953), Ericsson (1954) entre outras.

Vieira (2009, p. 18) esclarece sobre o crescimento e o desenvolvimento econômicos, apontando para a característica quantitativa do termo crescimento econômico, que pode ser mensurado através do PNB (Produto Nacional Bruto), da produção de bens e serviços, receita nacional poupada e investida e grau de aperfeiçoamento tecnológico. "O desenvolvimento econômico é o crescimento econômico acompanhado pela melhoria do padrão de vida da população e por alterações fundamentais na estrutura econômica e social” (VIEIRA, 2009, p. 18). O desenvolvimento engloba estes conceitos e é, a priori, menos quantificável e mais qualificável.

Percebe-se, hoje, que novos fatores como o capital social e o bem estar social vêm sendo incorporados no apontamento do desenvolvimento, desatrelando-o, inclusive, das ideias de 
progresso e industrialização. Para o pesquisador, o desenvolvimento humano promove a criação de oportunidades sociais, o que "contribui diretamente para a expansão das capacidades humanas e da qualidade de vida" (SEN, 2010, p. 62, 191). Não obstante, em sua análise, a expansão do desenvolvimento humano é também conducente à possibilidade de crescimento econômico, e aponta "sua influência sobre as habilidades produtivas das pessoas e, portanto, sobre o crescimento econômico em uma base ampliada".

Dentre as diferentes abordagens teóricas do desenvolvimento, este estudo, destarte, se identifica principalmente com os conceitos presentes na obra de Sen (2010) ao estudar a comunicação pública da ciência como fator contribuinte do desenvolvimento regional; tão pouco quantificável no escopo de determinadas abordagens clássicas, mas fortemente ancorada em casos admiráveis de recuperação e expansão econômica como os do Japão e outros países do Leste Asiático (SEN, 2010, p. 191).

\section{A Ciência, o conhecimento científico e o patrimônio científico valeparaibano}

Os apontamentos de historiadores, ao contar a história da ciência, o fazem com referências de milênios e, por toda a complexidade que representa o tema, não convém descrever o longo caminho histórico. Porém, é importante demarcar o renascimento científico - esse importante período na história da ciência que vai, entre tantos feitos, contribuir para a descoberta do Brasil - e o século XIX - principalmente após a chegada da família real ao país, quando começa a fortalecer a ciência nacional. Estes são períodos importantes para levantar os aspectos que constituem o conhecimento científico e sua instituição em solo valeparaibano.

Para Ronam (1987a, p. 12), a ciência demonstrou-se enorme aventura intelectual, atraindo "alguns dos melhores intelectos de cada civilização". O pesquisador define ciência como "um sistema de correlação lógica dos fatos que, juntos, consolidam uma hipótese ou o corpo de uma teoria [...] temperada pelas perspectivas proporcionadas pelos tempos em que é formulada".

Barros (apud HENRY, 1998, p. 10) afirma que vários pensadores foram influenciados pelo humanismo renascentista, "que coloca no homem a possibilidade (e a obrigação) de entender o mundo que se apresenta muito complexo". O espírito humanístico que conduz essa transformação chamada de Renascença vem superar o misticismo e o ascetismo da idade média. Inspirada pela Renascença, surgida na Itália, ensaia-se no século seguinte a Revolução Científica, "que mudou a forma de encarar a natureza e que gerou a moderna concepção científica” (RONAM, 1987b, p. 7). 
Este período, definitivamente marcado pela exploração geográfica, faz o Brasil surgir ao mundo através da exploração marítima portuguesa. Embora alguns autores discutam sobre a existência e a extensão da atividade científica em solo brasileiro a partir de sua descoberta, não há dúvidas de que a chegada da família real à colônia, em 1808, deu grande impulso à ciência nacional.

Algumas medidas aplicadas por D. João VI, em destaque a abertura dos portos, conduziram à "formação de um novo ambiente cultural" (FERRI; MOTOYAMA, 1979 p. 67). Inicialmente, e rapidamente conforme demonstram as datas, foram criados em 1808, o Colégio Médico da Bahia (a partir de 1832, Faculdade de Medicina da Bahia), a Escola Médica do Rio de Janeiro (também Faculdade de Medicina, em 1832) e o Horto (que originou o Jardim Botânico do Rio de Janeiro). Em 1810, foi criada a Academia Militar do Rio de Janeiro, que daria origem, em 1855, à Escola Central. Em 1874, surgiu a Escola Politécnica e, por fim, em 1818, o Museu Real (depois Museu Nacional de História Natural). Neste período, instalaram-se no Vale do Paraíba diversos viajantes europeus para registrar a região com absoluto rigor. Deu-se início à vocação científica valeparaibana, que atualmente desponta internacionalmente, e os documentos gerados à época, servem à ciência ainda hoje.

\section{Comunicação Científica e cidadania na sociedade da Informação}

Entende-se neste estudo que, ao tratar-se de desenvolvimento, há uma via a ser desbravada calcada na produção, qualidade e disseminação da informação, sobretudo científica. Indica-se que “dificilmente alguém discordaria de que a sociedade da informação é o principal traço característico do debate público sobre o desenvolvimento, seja em nível local ou global” (WERTHEIN, 2000, p. 71). Isso se dá, segundo o pesquisador, em parte pelo distanciamento crescente que se estabelece entre os que têm acesso aos mecanismos disseminadores da informação - com capacidade de digerir e refletir sobre os conteúdos - e aqueles que passam à margem de todo esse processo, sem acesso ou inaptos para a compreensão e reflexão da informação consumida. Sobre este último grupo é que pesa o intuito da presente pesquisa, uma vez que tal característica se dá pela inacessibilidade à informação e, quando esta existe, pela incapacidade de apreender conhecimento - estes são problemas crônicos que passam pela restrita e desqualificada estrutura nacional de acesso à rede mundial de computadores e pelo deficiente sistema educacional brasileiro (WERTHEIN, 2000). E, para lidar com a sociedade intensiva em conhecimento, Demo alerta que "é imprescindível dotar-se das 'habilidades do século XXI', entre elas, lidar bem com o conhecimento científico" (2010, p. 55).

Comun \& Info, v. 16, n. 2, p. 23-39, jul./dez. 2013 
Instala-se, neste momento, forte crítica ao sistema educacional do país pois, conclui o pesquisador, "no primeiro mundo se pesquisa; no Terceiro Mundo se dá aula".

Há na realidade brasileira um apontamento muito claro sobre a deficiência do sistema educacional. $\mathrm{O}$ ensino das ciências no Brasil enfrenta sérias dificuldades, como demonstram os relatórios do Pisa (Programa Internacional de Avaliação dos Estudantes) nas edições de 2000, 2003, 2006 e 2009. Oscilando entre perdas e ganhos trienais, o Brasil permanece invariavelmente entre as piores avaliações do ranking, com média muito aquém dos principais países. Observam Gois e Pinho (2007) e Waiselfisz (2009) que pior que estar nas últimas colocações, são as notas obtidas pela avaliação. O Brasil, afirmam os pesquisadores, alcança com dificuldade o nível 1, dentro de uma escala de proficiência com níveis de 1 a 6 . "Além de estarem entre os piores nas três provas nessa lista de países, a maioria dos estudantes brasileiros atinge, no máximo, o menor nível de aprendizado nas disciplinas" (GOIS; PINHO, 2007 s/p). O nível 1 representa domínios muito básicos a respeito dos temas avaliados.e os alunos "evidenciam um padrão de conhecimento científico tão limitado que só conseguem aplicá-lo a umas poucas situações familiares ou apresentar explicações científicas óbvias que se seguem quase imediatamente a uma evidência apresentada". (WAISELFISZ, 2009, p. 26).

Boczko (2005, p. 177) aponta para o "ciclo pernicioso" da educação, donde "o saber cultural e científico no Brasil é longevo, arraigado e altamente inerte a mudanças". Para Demo (2010), o problema grave está sobre os professores. Adianta que não se trata de apontamento a nível pessoal, mas institucional, uma vez que a prática pedagógica instrucionista reproduz-se desde os anos iniciais e refletem, já institucionalizadas, na formação de novos professores. Para o autor, o professor que não pesquisa não sabe ensinar a pesquisar. Posicionamento compartilhado por Pavan (2005, p. 103), que ainda estende o olhar crítico ao distanciamento dos pesquisadores que seguem "lutando e defendendo a bandeira de mais produção do conhecimento de fronteira, sempre financiada, e quase nunca aportam nas margens do ensino básico" e, ainda, pouco fazem por "novas metodologias e reformas de ensino necessárias".

Outros estudos têm demandado conhecimento e observação a respeito da divulgação científica e o papel do jornalista científico na missão de alfabetização científica na sociedade brasileira. Gonçalves, Graça e Pechula (2011, p. 2) afirmam que "a inserção das mídias de divulgação científica no contexto da sociedade atual é polêmica, mas inevitável”, além do que "ocupam função importante e complementar no exercício de construção do conhecimento".

Comun \& Info, v. 16, n. 2, p. 23-39, jul./dez. 2013 
Quanto ao acesso à informação, adverte Werthein (2000 p. 73) que “já é lugar comum a distinção entre países 'ricos' e países ‘pobres' em informação”. Nesse contexto, o comunicador de ciências assume uma condição relevante, pois "nos países mais avançados, o público está bastante a par dos principais conhecimentos científicos. Bueno (s/d) afirma que o "jornalismo científico tem um importante papel social a cumprir" e destaca a "função eminentemente pedagógica a ser cumprida pela mídia, complementar ao da educação" e a capacidade de através dos meios de comunicação de massa promover a "democratização do conhecimento científico, ampliando o debate sobre temas relevantes de ciência e tecnologia".

Observa-se na literatura que compreender a ciência pode estimular a prática da cidadania e a interferência nos processos locais ou mundiais se dá efetivamente pelo acesso à informação e pelo uso adequado da rede mundial de computadores. Logo, percebe-se que o amadurecimento da cidadania é um processo certo para o desenvolvimento de uma sociedade, desde que articulada, integrada e interada nas questões científicas. Pereira, Serra e Periço (2003, p. 157) afirmam que "o exercício consciente da cidadania não obriga ao conhecimento dos mecanismos internos do saber científico". Não se trata de "explicar ao grande público a física subjacente ao funcionamento de uma central nuclear, ou fazê-lo entender os processos químicos da vida", mas, sim, posicioná-lo de forma crítica sobre "a proliferação de centrais nucleares ou sobre questões da genética que interferem a reprodução humana". Retoma-se, assim, os apontamentos de Demo (2010, p. 55), onde a capacidade de produzir conhecimento inovador, e não apenas reproduzi-lo, é fator condicionante no distanciamento entre nações.

\section{Internet como ferramenta para popularização da Ciência}

A ciência aliou-se ao jornalismo após cerca de 200 anos da invenção da máquina de tipos móveis pelo alemão Johan Gutenberg. Desde então, a imprensa aprimorou seus meios e apropriouse de todas as novas tecnologias surgidas, como o rádio, a televisão e a web, adaptando a linguagem de maneira apropriada à particularidade de cada veículo. Ainda assim, a ciência encontra sérios problemas em sua transmissão por diversos motivos.

Para tratar do rádio, Werneck (2002, p. 83) salienta as dificuldades de se obter espaço e transmitir informação científica pelo meio, embora exponha toda a potencialidade do rádio em chegar a qualquer parte do país e em falar a todos os públicos. Há um claro "desinteresse do rádio pela pesquisa científica "não-sensacionalista'”. Sobre a televisão, Sousa (2003) retoma o debate da problemática relação entre o discurso científico e o midiático. Segundo o pesquisador, a televisão 
não abre espaço adequado à divulgação científica nos telejornais pelo próprio formato adotado pelo meio na transmissão da notícia. Tem-se, também, a possibilidade de acessar programações inteiramente dedicadas a estudos e experimentos científicos, mas estas são restritas a canais pagos em sistemas fechados de transmissão.

Macedo-Rouet (2003) destaca que a Internet revolucionou o acesso à informação científica. Tal fato se dá por todas as facilidades e liberdades pertinentes a essa mídia que, na opinião dos especialistas pode, a um só tempo, facilitar ou dificultar o acesso à informação. Por exemplo, a falta de domínio sobre as técnicas de busca, segundo Macedo-Rouet (2002, p. 185-186), pode interferir na filtragem de fontes, conduzindo a leituras de fontes não confiáveis. Ou ainda, mesmo que a experiência da hipertextualidade represente alternativas para o estabelecimento da informação, esta pode, se mal construída, segundo a pesquisadora, conduzir o leitor para fora do propósito inicial da leitura.

A estrutura da internet faz a exigência mínima para se ter acesso a ela. Este já é, por si só, grande problema, capaz de segregar indivíduos, localidades, regiões, nações (Castells, 2011; Werthein, 2000). Segundo o Mapa da Inclusão Digital (NERI, 2012, p. 13) o estudo da internet inclui ponderar, não somente o acesso, mas também a convergência, o conteúdo e a finalidade. "Conectividade significa poder acessar tecnologias de informação e comunicação (TICs)" seja pela internet ou telefonia. A convergência, explica, recai sobre as possibilidades de unificar o acesso em um mesmo dispositivo, como fazem hoje televisores e vídeo games, que como computadores e telefones, permitem acessar e navegar na internet. E, a partir da conquista do acesso, é preciso avaliar o conteúdo e a forma como este se apresenta para que se interrogue sobre sua finalidade. Nestas duas características finais apresentam-se a capacitação individual diante do novo meio, pela qual o usuário pode desfrutar objetivamente e qualitativamente. Este pesquisador alinha-se, aqui, ao discurso de Sen (2010), pelo qual a expansão das capacidades e de possibilidades permite ao indivíduo ampliar suas liberdades de escolha.

O ranking apresentado no Mapa da Inclusão Digital (MID), com base no acesso domiciliar para indivíduos acima de 15 anos, aponta o Brasil na $63^{\circ}$ colocação entre 154 países analisados. O acesso domiciliar contempla somente $33 \%$ da população nacional, enquanto nos países que lideram essa relação, o acesso chega a 97\% na Suécia, 94\% na Islândia, 92\% na Dinamarca e 91\% na Holanda. Das posições seguintes ocupam-se o bloco de países do oriente, com 89\% para Singapura, 87\% para a República da Coréia e 85\% para Hong Kong.

Comun \& Info, v. 16, n. 2, p. 23-39, jul./dez. 2013 
Aponta o MID que a taxa brasileira está exatamente sobre a média mundial, com os mesmos $33 \%$ de acesso. Com dados da Pesquisa Nacional por Amostra de Domicílios (PNAD) divulgada em setembro de 2012, aponta que, embora tenha avançado em relação aos anos anteriores, a internet chega somente a $46,5 \%$ da população nacional. Através da PNAD observa-se que, em período de seis anos, o acesso à internet avançou consideravelmente, sendo que, em 2006, estava acessível a somente $8 \%$ dos lares brasileiros.

O estudo do MID direcionado a RMVP revela dados sobre a porcentagem de domicílios com computador e a porcentagem de conexão através dessa estrutura domiciliar: computador + internet. A média nacional para computadores em domicílio é de $41,11 \%$. Para o estado de São Paulo é de 43,86\%. A RMVP aparece abaixo dessas médias, com 40,78\% dos domicílios da região contendo computador. Sobre a conexão domiciliar a partir de computadores, a RMVP também apresenta índices abaixo da média estadual e nacional. São 31,54\% de computadores conectados na RMVP, contra 37,39\% no Estado e 33,20\% no país. A observação mais aprofundada demonstra a discrepância regional nas duas condições de acesso estudadas. Tem-se que São José dos Campos, $26^{\circ}$ colocada no ranking nacional, lidera a região com $64,86 \%$ de computadores em domicílio, contra os $16,70 \%$ de Natividade da Serra, $3222^{\circ}$ colocada no ranking nacional. Sobre a Conexão a partir de Computadores em Domicílio, São José dos Campos, $28^{\circ}$ colocada no ranking nacional, lidera a região com $54,11 \%$. O pior índice de conectividade regional fica para Redenção da Serra, $3571^{\circ}$ no quadro nacional, com somente $8,97 \%$ de computadores domiciliares conectados. .

Embora primordial, a questão da acessibilidade não encerra a discussão sobre a transmissão do conhecimento científico. Atualmente, a dinâmica da divulgação científica dirigida aos pares encontram-se, além dos tradicionais impressos, nas publicações on-line. E um debate mundial vem despertando a atenção, pois trata do acesso livre a este material científico. A discussão se estende para além das possibilidades ou não de acesso, como interessa primordialmente à comunicação destinada ao grande público. O debate envolve grandes editores, direitos do leitor, custos ao leitor, direitos autorais, direitos de divulgação e custos de reprodução e divulgação, e por isso não é simples. Explica Marques (2012, p. 36) que a iniciativa de disponibilizar material científico com acesso aberto surgiu nos anos 1990 e hoje já é uma realidade a ser considerada; "atualmente, mais de $20 \%$ dos resultados de pesquisa no mundo são publicados em regime de acesso aberto" (MARQUES, 2012, p. 36), e aponta o Reino Unido como grande força nessa batalha, disponibilizando $35 \%$ dos seus artigos a esse modelo de divulgação.

Comun \& Info, v. 16, n. 2, p. 23-39, jul./dez. 2013 
Exemplo nacional de repositório de acesso aberto é a biblioteca on-line SciELO Brasil, cujo volume de artigos gratuitos baixados em sua coleção chega, mensalmente, à casa dos 36 milhões. O Brasil, por sinal, segundo dados do DOAj (Diretório de Revistas de Acesso Aberto), é o segundo no ranking de países com número de revistas com acesso aberto contabilizadas em 2012. Nas palavras de Ortellado (apud MARQUES, 2012, p. 38), "a trajetória do Brasil é única no mundo". Ao apontar a estratégia nacional com base na criação da biblioteca SciELO Brasil, o pesquisador afirma que o país possui uma política de acesso aberto bem-sucedida, "uma espécie de 'via diamante', pois sustenta um conjunto de revistas em acesso aberto com investimentos públicos e, na maioria das vezes, não cobra nada dos autores para publicar".

Todo este conteúdo está, portanto, disponível a todos os públicos, porém, observa-se um mínimo de exigência para usufruí-lo Além da necessidade de meio para conectar-se e conexão disponível, o indivíduo precisa ter alguma familiaridade com o sistema de pesquisa que, a rigor, pelos motivos já explicitados, cobra dos usuários alguma educação baseada na proximidade com a produção científica.

\section{Resultados e Discussão}

Embora seja percebida na literatura a tentativa de associar a compreensão pública da ciência à promoção do bem estar econômico e social do indivíduo, pouco se encontra a respeito quando o estudo envolve a Região Metropolitana do Vale do Paraíba. Por esse motivo, o presente estudo buscou, além da literatura, realizar investigações pertinentes à região estudada.

Para que se pudesse entender sobre a dinâmica da produção e divulgação científica na região, dois pontos fundamentais serviram de alicerce na investigação: a observação da produção científica, coletando dados dos Indicadores Regionais de Produção científica do Vale do Paraíba Paulista (SANTOS, 2007) e realizando levantamento junto à comunidade científica regional, e a observação da mídia escrita, fosse eletrônica ou impressa.

Observou-se, a partir de dados do Projeto Donos da Mídia, cujo levantamento considera apenas os veículos devidamente registrados em órgãos oficiais, que a região apresenta 26 jornais e 2 revistas. A contar que a RMVP possui 39 cidades, não se alcança a possibilidade de que cada cidade tenha seu próprio jornal. Assim como as revistas, nenhum dos jornais observados possui viés científico; embora O Vale, principal jornal regional, sediado em São José dos Campos, apresenta, rotineiramente, assuntos de cunho científico e, não raramente, traz às suas matérias a opinião de 
pesquisadores regionais. Quanto à internet, identificam-se canais com informação científica generalizada, cuja a ciência regional é pequena parte e não merece dedicação exclusiva.

Sobre os sites das instituições de pesquisa objeto da presente pesquisa, constatou-se que todas as instituições abordadas para esta pesquisa apresentam acesso ao conhecimento por elas desenvolvido. Como este conteúdo está imerso no universo de informações eleitas ao grande público, fica, por vezes, difícil, detectar o propósito de divulgar publicamente os feitos científicos. Porém, após alguns caminhos chega-se ao material científico, ora em formato noticioso, ora com acesso ao texto original (tese ou dissertação). Através do site da UNESP de Guaratinguetá, a única das instituições pesquisadas a publicar os dados de acesso, pôde-se ter com precisão o balanço de acesso público ao material científico regional - no caso o produzido somente pela UNESP de Guaratinguetá. A média mensal, bastante representativa, obtida entre maio e novembro de 2012 beira os 23 mil acessos em uma de suas comunidades. Sendo que este não representa sítio próprio para a divulgação científica ao grande público, ou público leigo, cabe concluir que a própria comunidade científica e afins demonstram interesse pelo que se pesquisa em solo valeparaibano.

Sobre o interesse público nos assuntos científicos, o Ministério da Ciência Tecnologia e Inovação (MCTI) apresentou, em 2010, a pesquisa sobre a Percepção Pública da Ciência. Em suas conclusões gerais, o relatório da pesquisa afirma que há interesse relativamente grande pela ciência (PERCEPÇÃO PÚBLICA DA CIÊNCIA, 2010, p. 71). Mesmo com a inexistência de um indicador regional a este respeito, entende-se para a presente investigação que esta pesquisa de âmbito nacional traduz, também, o perfil do Vale do Paraíba.

Santos (2007) identificou que a produção científica do Vale do Paraíba Paulista, lê-se neste estudo Região Metropolitana do Vale do Paraíba, decorria do trabalho de 268 grupos de pesquisa cadastrados no CNPq. Estes englobavam 988 linhas de pesquisa das quais a grande parte estava dedicada às Engenharias e às Ciências Exatas e da Terra (SANTOS, 2007, p. 102). No total, a região abordada abrigava o trabalho de 1.628 pesquisadores, $5 \%$ do total de pesquisadores para o estado de São Paulo. Ainda na comparação estadual, o Vale representava 4,8\% dos grupos de pesquisa, $12,5 \%$ da produção bibliográfica, $10,8 \%$ da orientação concluída e cerca de $25 \%$ dos trabalhos completos publicados nos eventos científicos. Desta produção bibliográfica de trabalhos concluídos publicados, as Engenharias eram responsáveis por 74\% do volume total (SANTOS, 2007, p. 118). Estes dados conduzem ao entendimento de que há vasta quantidade de material a circular. 
A partir de busca junto ao SEER (Sistema Eletrônico de Editoração de Revistas) obteve-se que a região Sudeste tem 378 revistas cadastradas naquele sistema. Dessas, 231 pertencem ao estado de São Paulo. Observando-se a região estudada têm-se a seguinte distribuição: Taubaté, com sete revistas, São José dos Campos, Lorena e Guaratinguetá, com duas revistas cada. Essa busca refinada aponta que a RMVP é responsável por 5,6\% das revistas cadastradas para o estado.

O questionário aplicado aos líderes dos grupos de pesquisa cadastrados no CNPq e atuantes na RMVP traz outras considerações importantes neste quadro que se desenha nesta pesquisa. Dividido em três seções investigou sobre a associação dos pesquisadores com as premissas desta pesquisa, sobre a relação dos pesquisadores com a mídia e, finalmente, sobre a percepção dos pesquisadores sobre a divulgação pública da ciência regional nos veículos de comunicação de massa da região. A forte resistência à colaboração com a presente pesquisa resultou na ausência de $10 \%$ da amostragem mas, sem dúvida, deu indícios significativos.

Todos os respondentes são unânimes sobre a importância de se divulgar ciência ao público, mas somente $18 \%$ entendem-se como responsáveis pelo ato. Baseado nas premissas apresentadas neste trabalho, obteve-se que $100 \%$ dos respondentes, concordando total ou parcialmente, entendem que o indivíduo, e consequentemente a sociedade, carecem do conhecimento sobre assuntos científicos para o exercício cidadão de fato. Do mesmo modo, o conhecimento científico mostra-se primordial para que indivíduo e sociedade manifestem-se em favor da interferência nas diretrizes políticas e econômicas locais e regionais.

A segunda seção do questionário inclinou-se na investigação da relação dos pesquisadores com a mídia e constatou que a maioria, 55\%, acompanha a divulgação pública da ciência através dos meios de comunicação de massa com frequência. Os principais meios de comunicação de massa (MCM) utilizados são a revista e a internet, com $82 \%$ de preferência cada. Destaca-se a perda significativa de preferência da Revista Impressa quando se sai da posição de consumidor (82\%) para assumir o posto de fomentador $(50 \%)$ da informação científica. Nesse ponto a Internet surge como o MCM preferido pelos pesquisadores para divulgar seus trabalhos ao grande público, mantendo-se com preferência na casa dos $80 \%$ dos respondentes. Portanto, a Internet é o mais importante canal para consumir e comunicar ciência.

Quando perguntado se já havia participado de reportagem falando sobre assuntos relacionados à ciência através dos meios de comunicação de massa, o Jornal Impresso, a Revista Impressa e a Televisão lideraram as escolhas com $18 \%$ cada. A Internet já serviu de canal de comunicação a somente $9 \%$ dos pesquisadores. Sobre a expectativa de participação, obteve-se que 
9\% não têm interesse em falar de ciência ao grande público contra $27 \%$ que jamais participaram mas esperavam pela oportunidade. A Revista Impressa, a Televisão e o Rádio, todos com 18\%, já serviram aos pesquisadores para divulgação pública de seus trabalhos. A Internet não abrigou nenhum dos pesquisadores consultados. É possível levantar algumas discussões a partir destes resultados obtidos.

Primeiro, que obteve-se baixas respostas, pois nenhum veículo atendeu, se quer, $30 \%$ dos pesquisadores, fosse para falar sobre ciência ou sobre pesquisa própria. Aqui se revelam outras duas questões; as editorias de ciência dos veículos regionais utilizam muito pouco a opinião científica regional na composição de suas reportagens e, do mesmo modo, abrem pouco espaço para que se divulgue a produção científica da RMVP. Segundo, que $9 \%$ dos pesquisadores demonstraram não ter interesse em falar sobre ciência ao grande público. Esse desinteresse não só vai de encontro à instituição científica como contribui para a privacidade à liberdade de escolha pregada por Sen (2010). Se não se comunica a ciência, não se dá possibilidade ou oportunidade às pessoas para que ampliem seus conhecimentos. Demo (2010, p. 32) reforça esta ideia ao afirmar que "conhecer é, eminentemente, questionar, o que supõe a noção dinâmica, rebelde e disruptiva do conhecimento científico".

O passo seguinte propôs avaliar a motivação para a publicação de suas pesquisas. Os MCM de circulação internacional receberam a indicação de $45 \%$ dos que entendem ser Muito Importante ou Importante. Os MCM de circulação nacional estimulam 54\% dos pesquisadores que o consideram Muito Importante e Importante. Os mesmos dados repetem-se para os MCM de circulação Regional/Local. Para o caso de publicação dirigida, a Revista Especializada de circulação internacional surge com $100 \%$ dos pesquisadores julgando-a ser Muito Importante. Observa-se, aqui, que o prestígio é fator preponderante na divulgação científica.

Concluindo o levantamento, obteve-se que somente $9 \%$ dos entrevistados acompanham a produção científica valeparaibana, $18 \%$ o fazem eventualmente e $64 \%$ não o fazem. A divulgação da ciência regional é Pouco Divulgada para $82 \%$ e Não é Divulgada para $18 \%$ dos respondentes. Pode-se considerar a partir destes dados a presença de um ciclo pernicioso em torno da divulgação regional. Tamanha rejeição à ideia de se acompanhar as notícias sobre a produção científica valeparaibana pode-se justificar pela pouca ou nenhuma divulgação dela decorrente. Do mesmo modo, a ciência regional se caracteriza pela pouca ou nenhuma divulgação, possivelmente, pelo desinteresse em acompanhar estas notícias e, principalmente, pelo desinteresse dos próprios pesquisadores em fomentar esta rede de informação. 
$\mathrm{O}$ entendimento dos pesquisadores a respeito do que se conhece e do que se deveria conhecer sobre a ciência regional apontou que 54\% dos pesquisadores acreditam que a mídia regional permite que se conheça sobre os pesquisadores da região; $81 \%$ concordam que a mídia regional deveria permitir que se conhecesse sobre os pesquisadores. Os resultados também são mais favoráveis à possibilidade de reconhecimento quando observadas as possibilidades de reconhecimento das instituições de pesquisa e das áreas pesquisadas. O cruzamento dos dados revelou que grande parte dos pesquisadores espera por reconhecimento e prestígio mesmo a nível regional/local.

Para o fato de a divulgação regional motivar o surgimento de novos pesquisadores, apurouse grande divisão de opiniões entre a concordância e a discordância. Para a hipótese de que deveria motivar o surgimento de novos pesquisadores obteve-se $91 \%$ de concordância. Torna-se claro, na opinião dos pesquisadores, que a divulgação científica regional seria um meio plausível para o incentivo à busca de informação científica e que, principalmente, seria igualmente importante na condução de jovens estudantes para a carreira acadêmica da pesquisa. Fato é que, embora tenha-se levantado anteriormente que a divulgação científica a nível regional/local não estimula a participação dos pesquisadores, para o caso da existência de um veículo destinado exclusivamente a este fim, o comprometimento em maior ou menor grau alcançaria $91 \%$ da comunidade científica da RMVP.

\section{Considerações finais}

As ferramentas políticas empregadas pelos municípios da região têm, até o momento, perpetuado fortes diferenças intrarregionais e contribuído pouco para o desenvolvimento equânime entre as cidades. Isso reflete em índices sobre economia, educação, saúde, emprego, pesquisa etc. Não se percebe no horizonte próximo nada que seja capaz de provocar mudanças drásticas e rápidas; qualquer alteração demanda planejamento e tempo.

Estudar a divulgação pública da ciência nesse contexto é um desafio, uma vez que o tema, apesar de estar tão próximo do cotidiano das sociedades, parece ainda estar distante de ser compreendida e aceita por grande parte das populações. Trazer o tema para o âmbito regional é, além de adequado, um passo decisivo para tornar o debate vivo entre os agentes transformadores locais. Como visto, a influência desses agentes sobre as regiões é fator preponderante na discussão e adoção de políticas públicas condizentes com cada realidade regional em específico. 
Expor a ciência valeparaibana, então, parece uma obrigação acima de tudo. Esta não é uma região que faz ciência por acaso, o que torna primordial o fortalecimento informacional da rede científica. Primeiro para alimentar a própria ciência ali produzida; segundo para oferecer ao grande público a oportunidade de conhecer a ciência regional e se aproximar do universo científico.

Conclui-se que a divulgação regional existe, é falha, mas pode ser pensada como um caminho de oportunidade ao público. Em última análise, pelas questões levantadas na literatura, a ciência é um caminho para a criação de oportunidades, de possibilidades quem ampliem a liberdade de escolha e, consequentemente, o desenvolvimento humano.

\section{Referências}

BOCZKO, Roberto. A precisão científica na educação e na cultura. In: WERTHEIN, J.; CUNHA, C. (Orgs.). Educação científica e desenvolvimento: o que pensam os cientistas. 2005. Disponível em: <http://pt.scribd.com/doc/9707277/Educacao-Cientifica-e-to-o-Que-Pensam-Os-Cientistas>. Acesso em: 20 maio 2011.

BRANDÃO, Carlos. Território e desenvolvimento: as múltiplas escalas entre o global e o local. Campinas: Editora da UNICAMP, 2009.

BUENO, Wilson da C. Jornalismo científico e democratização do conhecimento. Disponível em: <http://www.jornalismocientifico.com.br/jornalismocientifico/artigos/jornalismo_cientifico/artigo2 7.php>. Acesso em: 7 dez. 2010.

CASTELLS, Manuel. A sociedade em rede: a era da informação: economia, sociedade e cultura. v. 1. 14. reimp. São Paulo: Paz e Terra, 2011.

DEMO, Pedro. Educação e alfabetização científica. São Paulo: Papirus Editora, 2010.

FERRI, Mário G.; MOTOYAMA, Shozo. História das ciências no Brasil. São Paulo: EPU/Edusp. 1979.

GOIS, Antônio; PINHO, Angela. Brasil é reprovado, de novo, em matemática e leitura. Folha de S. Paulo, São Paulo, 05 dez. 2007. Disponível em:

<http://www1.folha.uol.com.br/folha/educacao/ult305u351481.shtml>. Acesso em 18 dez. 2011.

GONÇALVES, Elizabeth; CALDAS, Graça; PECHULA, Márcia R. Mídia e educação: reflexões sobre o uso pedagógico de textos de divulgação científica. 2011. Disponível em: <http://www.mc.unicamp.br>. Acesso em: 15 dez. 2011.

HENRY, John. Revolução científica e as origens da ciência moderna. Rio de Janeiro: Jorge Zahar, 1998.

KRASILCHIK, Myriam. Reformas e realidade: o caso do ensino das ciências. 2000. Disponível em: <http://www.scielo.br/pdf/spp/v14n1/9805.pdf>. Acesso em: 05 jul. 2011.

Comun \& Info, v. 16, n. 2, p. 23-39, jul./dez. 2013 
KRASILCHIK, Myriam. Caminhos do ensino de ciências no Brasil. Em Aberto, Brasília, ano 7, n. 40, out./dez. 1988. Disponível em:

<http://emaberto.inep.gov.br/index.php/emaberto/article/viewFile/811/729>. Acesso em: 05 jul. 2011.

LEMOS, Maurício B. Espaço e capital: um estudo sobre a dinâmica centro x periferia. 1988. Disponível em: <http://cutter.unicamp.br/document/?code=vtls000150067>. Acesso em: 12 jul. 2011.

MACEDO-ROUET, Mônica. Revistas de divulgação científica: do texto ao hipertexto. In: MASSARANI,L.; MOREIRA, I. C.; BRITO, F. (Orgs.). Ciência e público: caminhos da divulgação científica no Brasil. Rio de Janeiro: Casa da Ciência, 2002.

Divulgação científica na Internet: mais e melhores fontes? 2003. Disponível em: <http://www.comciencia.br/reportagens/cultura/cultura10.shtml>. Acesso em: 20 fev. 2011.

NERI, Marcelo C. Mapa da inclusão digital. 2012. Disponível em: http://cps.fgv.br/telefonica>. Acesso em: 10 dez. 2012.

MARQUES, Fabrício. Conhecimento livre, Pesquisa FAPESP, n. 201, p. 35-39, 2012.

MARTINS, Jefferson; SANTOS, Moacir J. dos; CARNIELLO, Mônica F. Caminhos e rotas no desenvolvimento da região metropolitana do Vale do Paraíba: da mula ao trem bala. 2012a. Disponível em: <http://www.unitaupgrad.com.br>. Acesso em: 10 dez. 2012.

MARTINS, Jefferson; SANTOS, Ademir P. dos; CARNIELLO, Mônica F. O renascimento científico e a formação do patrimônio histórico científico do Vale do Paraíba Paulista. 2012b. Disponível em: <http://www.inicepg.univap.br>. Acesso em: 10 dez. 2012.

MARTINS, Jefferson; QUINTAIROS, Paulo C. R. Parque tecnológico: contribuições da pesquisa científica no processo de desenvolvimento regional. 2011. Disponível em:

<http://www.unitaupgrad.com.br/cd/index.html>. Acesso em: 26 ago. 2012.

PERCEPÇÃO Pública da Ciência. Ministério da Ciência, Tecnologia e Inovação. Disponível em: <http://www.mcti.gov.br>. Acesso em: 18 jun. 2011.

PEREIRA, Amélia; SERRA, Izabel; PERIÇO, Nuno M. Valor da ciência na divulgação científica. In: SANTOS, Milton. A urbanização brasileira. 5. ed. São Paulo: USP, 2008.

RONAN, Colin A. História ilustrada da ciência: Universidade de Cambridge. v.1. São Paulo: Jorge Zahar, 1987a.

RONAN, Colin A. História ilustrada da ciência: Universidade de Cambridge. v.3. São Paulo: Jorge Zahar, $1987 \mathrm{~b}$.

SANTOS, Terezinha Gomes dos. Indicadores regionais de produção científica: o caso do Vale do Paraíba Paulista. 2007. 152f. Dissertação (Mestrado em Gestão e Desenvolvimento Regional) Universidade de Taubaté, Taubaté, 2007.

Comun \& Info, v. 16, n. 2, p. 23-39, jul./dez. 2013 
SEN, Amartya. Desenvolvimento como liberdade. São Paulo: Companhia das Letras, 2010.

VIEIRA, José T. Industrialização e políticas de desenvolvimento regional: o Vale do Paraiba Paulista na segunda metade do séc. XX. 2009. Disponível em:

<http://www.teses.usp.br/teses/disponiveis/8/8137/tde-03022010-143611/pt-br.php>. Acesso em: 05 jun. 2011.

WAISELFISZ, Julio J. O ensino das ciências no Brasil e o Pisa. São Paulo: Sangari do Brasil, 2009. Disponível em: <http://www.dominiopublico.gov.br/download/texto/is000003.pdf>. Acesso em: 05 jul. 2011.

WERTHEIN, J.; CUNHA, C. (Orgs.). Educação científica e desenvolvimento: o que pensam os cientistas. 2005. Disponível em: <http://pt.scribd.com/doc/9707277/Educacao-Cientifica-e-to-oQue-Pensam-Os-Cientistas>. Acesso em: 20 maio 2011.

WERTHEIN, Jorge. A sociedade da informação e seus desafios. 2000. Disponível em: <http://www.scielo.br/pdf/ci/v29n2/a09v29n2.pdf>. Acesso em: 05 jul. 2011. 